\title{
Comparison of the photocatalytic degradation of trypan blue by undoped and silver-doped zinc oxide nanoparticles
}

\author{
T.N. Ravishankar a, K. Manjunatha ${ }^{\text {a }}$, T. Ramakrishnappa ${ }^{a}$, G. Nagaraju ${ }^{\text {a,b,*, }}$ \\ Dhanith Kumar ${ }^{\text {b }}$, S. Sarakar ${ }^{\text {c }}$, B.S. Anandakumar ${ }^{\text {d }}$, G.T. Chandrappa ${ }^{\mathrm{d}}$, \\ Viswanath Reddy ${ }^{\mathrm{e}}$, J. Dupont ${ }^{\mathrm{f}}$ \\ ${ }^{a}$ Centre for Nano and Material Sciences, Jain University, Jakkasandra, Kanakapura (T), India \\ b Department of Chemistry, BMS Institute of Technology, Bangalore, India \\ ${ }^{\mathrm{c}}$ Department of Inorganic and Physical Chemistry, Indian Institute of Science, Bangalore, India \\ d Department of Chemistry, Central College Campus, Bangalore University, Bangalore, India \\ e Liquid Crystal Research Center, Department of Chemistry, Hull University, Hull, United Kingdom \\ ${ }^{\mathrm{f}}$ Laboratory of Molecular Catalysis, Institute of Chemistry, UFRGS, Porto Alegre, Brazil
}

\section{A R T I C L E I N F O}

Keywords:

Silver doped zinc oxide

Combustion

Trypan blue

Optical properties

Degradation

\begin{abstract}
A B S T R A C T
Zinc oxide ( $\mathrm{ZnO}$ ) and silver doped zinc oxide ( $\mathrm{ZnO}: \mathrm{Ag}$ ) nanoparticles were prepared using nitrates of zinc and silver as oxidizers and ethylene diaminetetraacetic acid (EDTA) as a fuel via low-temperature combustion synthesis (LCS) at $500{ }^{\circ} \mathrm{C}$. X-ray diffraction (XRD) pattern indicates the presence of silver in the hexagonal wurtzite structure of $\mathrm{ZnO}$. Fourier transform infrared (FTIR) spectrum indicates the presence of $\mathrm{Ag}-\mathrm{Zn}-\mathrm{O}$ stretching vibration at $510 \mathrm{~cm}^{-1}$. Transmission electron microscopy (TEM) images shows that the average particle size of $\mathrm{ZnO}$ and $\mathrm{ZnO}: \mathrm{Ag}$ nanoparticles were found to be $58 \mathrm{~nm}$ and $52 \mathrm{~nm}$, respectively. X-ray photoelectron spectroscopy (XPS) data clearly indicates the presence of $\mathrm{Ag}$ in $\mathrm{ZnO}$ crystal lattice. The above characterization techniques indicate that the incorporation of silver affects the structural and optical properties of $\mathrm{ZnO}$ nanoparticles. $\mathrm{ZnO}: \mathrm{Ag}$ nanoparticles exhibited 3\% higher photocatalytic efficiency than pure $\mathrm{ZnO}$ nanoparticles. $\mathrm{ZnO}$ :Ag nanoparticles show better photocatalytic activity for the degradation of trypan blue ( $\mathrm{TrB}$ ) compared to undoped $\mathrm{ZnO}$ nanoparticles.
\end{abstract}

(c) 2014 Elsevier Ltd. All rights reserved.

\section{Introduction}

Nanocrystalline transition metal oxides have attracted wide attention due to their unique properties, which are technologically very useful in nano-device fabrications [1,2]. Amongst these materials, zinc oxide $(\mathrm{ZnO})$ nanoparticles were very interesting due to their semiconducting property with a band gap of $3.370 \mathrm{eV}$, a relatively high excitation binding energy ( $60 \mathrm{meV}$ ) and unique properties like promising photocatalyst, excellent piezoelectric and novel optical

\footnotetext{
* Corresponding author. Tel.: +91 8027506270.

E-mail address: nagarajugn@rediffmail.com (G. Nagaraju).
}

properties [3]. Various groups have used doped and undoped $\mathrm{ZnO}$ nanoparticles as photocatalyst for the degradation of organic dye. They found that undoped $\mathrm{ZnO}$ exhibited lower photocatalytic activity than the doped $\mathrm{ZnO}$ nanomaterials. This is because in pure $\mathrm{ZnO}$ the rate of electron-hole pair recombination is more than the doped $\mathrm{ZnO}$ nanomaterials $[4,5]$. Therefore, in order to enhance the photocatalytic activity of $\mathrm{ZnO}$ nanoparticles, noble metal incorporation, coupling with other semiconductors or by adding adsorbent to the $\mathrm{ZnO}$ have been carried out by various groups around the world [6,7]. Of these, noble metal ion incorporation have been studying extensively and proved to be very effective in improving the photocatalytic activity and also to tune the optical and electrical properties of $\mathrm{ZnO}$ [8]. Various groups 
have synthesized ZnO:Ce nanoparticles [9], ZnO:Pd nanoparticles [10], ZnO:Al nanoparticles [11], and ZnO:Mn nanoparticles [12] by different method and observed the improved performance compared to pure $\mathrm{ZnO}$ nanoparticles. Literature surveys suggested that $\mathrm{ZnO}$ or $\mathrm{ZnO}: \mathrm{Ag}$ is non-toxic in nature and are used in the various biological/medical applications [13]. However, inhalation or consumption of large quantity of $\mathrm{ZnO}$ or $\mathrm{ZnO}$ :Ag through food additives, synthesis or through any other way causes severe damages to living cells (olfactory epithelium) as reported by Gao et al. [14]. Mohamad reported that the consumption of $\mathrm{ZnO}$ nanoparticles causes liver problems [15]. Bondarenko et al. reported the in-vitro toxicity of $\mathrm{ZnO}: \mathrm{Ag}$ nanoparticles on mammalian cells [16]. Literatures survey suggested that the $\mathrm{ZnO}$ and $\mathrm{ZnO}: \mathrm{Ag}$ nanoparticles are physically and chemically stable. Susan et al. reported the synthesis of $\mathrm{ZnO}: \mathrm{Ag}$ heterostructure nanoparticles for antibacterial and thermal studies. They observed that $\mathrm{ZnO}: \mathrm{Ag}$ nanoparticles significantly increased the thermal stability of cellulose nanocrystals [17]. Rahman et al. observed that starch-based polymer $\mathrm{ZnO}$ nanoparticles show improved dielectric and conductive properties compared to pure $\mathrm{ZnO}$ nanoparticles [18]. Altıntas Ylldırım et al. synthesized $\mathrm{ZnO}: \mathrm{Ag}$ nanoparticles at room temperature and found $\mathrm{ZnO}: \mathrm{Ag}$ better than $\mathrm{ZnO}$ with respect to optical properties [19]. Teng et al. found vertically aligned $\mathrm{ZnO}: \mathrm{Ag}$ nanowires arrays for photo electrochemical applications better than bare $\mathrm{ZnO}$ nanoparticles [20]. Ozlem et.al [21] and Shah et.al [22] also observed similar improved photocatalytic and antibacterial activity in synthesized $\mathrm{ZnO}: \mathrm{Ag}$ nanoparticles. From all the above-stated literature, it is clear that $\mathrm{Ag}$ is one of the most promising dopant which alters the surface and fabrication of $\mathrm{ZnO}$ by decreasing the total volume of the particle which in turn, decreases the recombination probability making more carriers available for the oxidation/reduction on the surface [23]. The surface area and surface defects play an important role in photocatalytic activities of $\mathrm{ZnO}$ [24-26]. Various methods are available to prepare $\mathrm{ZnO}: \mathrm{Ag}$ nonstructural materials, a few of them are co-precipitation [27], hydrothermal [28], sol-gel method [29], electro deposition [30], solution combustion method [31] etc. Amongst the available methods, solution combustion method is considered simple, instantaneous, single-step and energy-saving. This method also produces homogenous, very fine crystalline product without intermediate calcinations or grinding [32,33]. Here we report the synthesis of $\mathrm{ZnO}: \mathrm{Ag}$ nanoparticles using nitrates of $\mathrm{Zn}$ and $\mathrm{Ag}$ as an oxidizers and ethylene diaminetetraacetic acid (EDTA) as a fuel by the low temperature combustion synthesis (LCS) method. EDTA is used as fuel because it is nontoxic, low cost, and rich in carbon, nitrogen, hydrogen and oxygen which are released as their corresponding gases during combustion. The release of these gases leads to the formation of highly porous, voluminous and high-surface area $\mathrm{ZnO}: \mathrm{Ag}$ nanoparticles. The obtained product shows good photocatalytic activity which has been studied using trypan blue, a toxic azo dye. Trypan blue has been used extensively in the textile, food and paints industries for dyeing nylon, wool, cotton, silk and also for coloring of oil, fats, waxes, varnish, plastics, etc. Dyes create several environmental problems by releasing highly carcinogenic molecules into the aqueous medium. Various techniques have been used for the removal of dyes

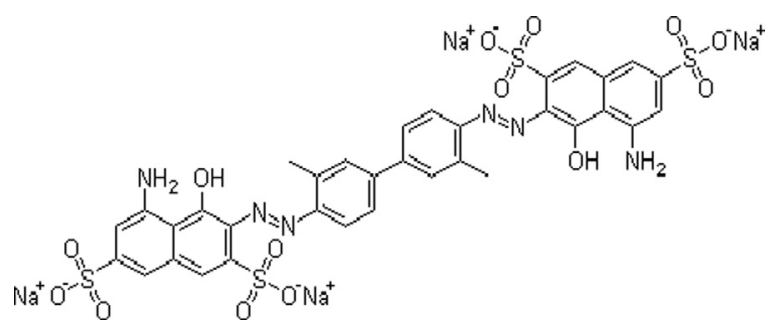

Fig. 1. Structure of trypan blue dye.

from the aqueous medium like biodegradation and photocatalytic degradation. Reviewing the available literature indicated that the biodegradation method cannot be used to degrade azo dyes [34]. Researchers show inclination towards photocatalytic degradation these days because the reactions are carried out under ambient conditions. The structure of dye can be shown in Fig. 1.

\section{Experimental method}

\subsection{Preparation of $\mathrm{ZnO}$ and $\mathrm{Ag}$ doped $\mathrm{ZnO}$ nanoparticles}

In order to prepare $\mathrm{ZnO}$ and $\mathrm{ZnO}: \mathrm{Ag}$ nanoparticles, nitrates of zinc and silver are used as oxidizers and EDTA as fuel. To remove the sodium ions from the salt, the disodium salt of EDTA is treated with $2 \mathrm{M} \mathrm{HCl}$ solution (Fig. 2). The obtained precipitate (EDTA) is washed several times with water to remove sodium ions and dried at $100{ }^{\circ} \mathrm{C}$ for $1 \mathrm{~h}$. The dried EDTA is used as fuel for the preparation of $\mathrm{ZnO}$ and $\mathrm{ZnO}: \mathrm{Ag}$ nanoparticles. Stoichiometric amounts of nitrates of zinc and silver as oxidizers and fuel (EDTA) in 1:1 ratio are taken in a trough; required amount of double distilled water is added. A good combination of fuel and oxidizer is one which is completely soluble in water to form homogenous redox solution. EDTA is sparingly soluble in cold water and completely soluble in hot water. The homogeneous redox solution is pre-heated on a hot plate at $150{ }^{\circ} \mathrm{C}$, until it forms gel on dehydration. This gel is introduced into a preheated muffle furnace maintained at $500{ }^{\circ} \mathrm{C}$; smoldering type of combustion takes place and within 3-4 min, the reaction proceeds to completion and forms nanocrystalline $\mathrm{ZnO}$. The products were calcined at $500{ }^{\circ} \mathrm{C}$ for $1 \mathrm{~h}$. The same procedure is followed for the preparation of $\mathrm{ZnO}: \mathrm{Ag}$ nanoparticles where the ratio is 1:0.5:1 (zinc nitrate:silver nitrate:EDTA).

\subsection{Characterization}

X-ray diffraction (XRD) data were recorded on Philips X'pert PRO X-ray diffractometer with graphite monochromatized $\mathrm{Cu}-\mathrm{K} \alpha(1.542 \AA$ ) radiation. X-ray photoelectron spectroscopy (XPS) analysis was carried out on an ESCALAB 250 (Thermo-VG Scientific), using $\mathrm{Al} \mathrm{K \alpha}$ as the excitation source. The instrument was standardized against the C1s spectral line at $284.600 \mathrm{eV}$. The Fourier transform infrared spectra (FTIR) of the samples were collected using Bruker Alpha-P spectrometer. The absorption spectra of the samples were measured on a Perkin Elmer Lambda-750 UV-vis spectrometer (Ultraviolet-visible). Photoluminescence (PL) spectra were examined by Perkin Elmer spectrometer using Xe lamp with an 
excitation wavelength of $330 \mathrm{~nm}$. The surface morphology was observed using Carl Zeiss ultra 55 scanning electron microscopy (SEM). Transmission electron microscopy (TEM) was performed JEOL JEM 1200 Ex operating at $100 \mathrm{kV}$. The surface areas of the samples were analyzed by Smart Sorb/93 Brunauer, Emmett and Teller (BET) surface analyzer (with

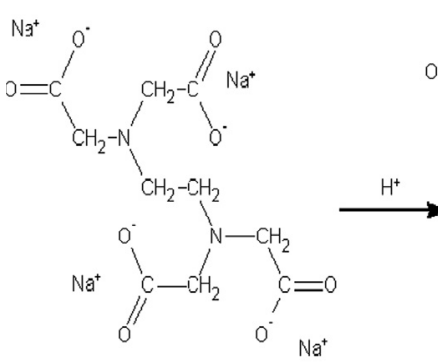

sodium salt of EDTA

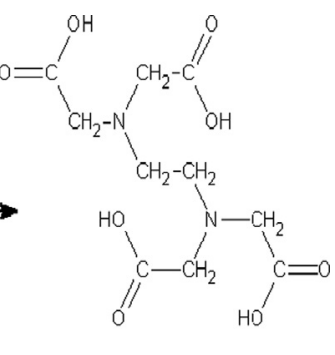

EDTA
Fig. 2. Conversion of sodium salt of EDTA to EDTA.

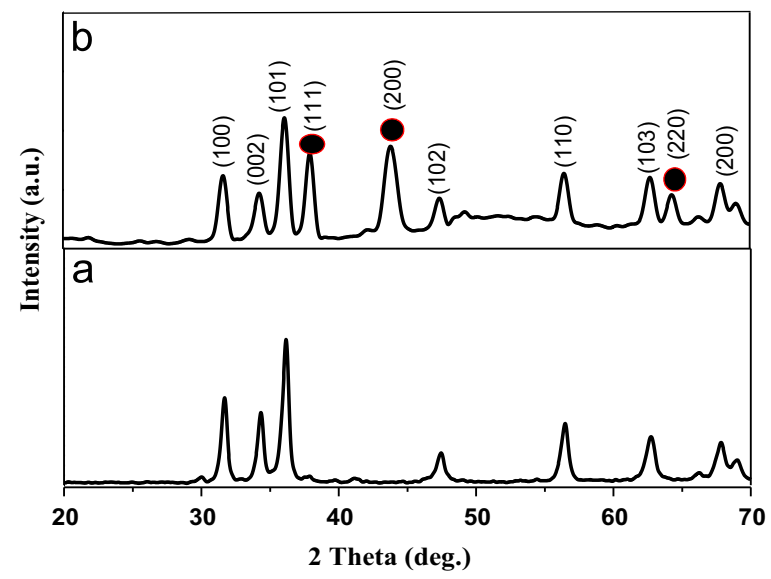

Fig. 3. (a) PXRD pattern of the $\mathrm{ZnO}$ and (b) $\mathrm{ZnO}: \mathrm{Ag}$ nanoparticles. sorb93 reduction software) and fluorescence intensity was measured by spectro-flurophotometer (Shimadzu, RF-5301PC Series).

\subsection{Experimental procedure for photocatalytic degradation of dye}

Photocatalytic experiments were carried out in a $150 \times 75 \mathrm{~mm}^{2}$ batch reactor. A catalytic load of $100 \mathrm{mg}$ in $100 \mathrm{~mL}$ of the dye was prepared. The $\mathrm{pH}$ of the solution was adjusted by addition of either $0.050 \mathrm{M} \mathrm{NaOH}$ or $0.050 \mathrm{M}$ $\mathrm{H}_{2} \mathrm{SO}_{4}$. The slurry composed of dye solution and catalyst was placed in the reactor and stirred magnetically for agitation with simultaneous exposure to sun light/UV light. Known volume of the slurry was withdrawn at specific interval of time, centrifuged to remove the interference of the catalyst and assessed using spectrophotometer $(592 \mathrm{~nm})$ for rate of degradation. The \% of degradation can be determined using the following formula shown in the Eq. (1).

$\%$ of degradation $=\frac{C_{i}-C_{f}}{C_{i}} \times 100$

$C_{i}$ and $C_{f}$ are the initial and final concentrations of dye. The experiment was carried out by varying experimental parameters like concentration of dye, catalytic load, irradiation time, $\mathrm{pH}$ and nature of light.

\section{Result and discussion}

Fig. 3 shows the XRD pattern of the $\mathrm{ZnO}$ and $\mathrm{ZnO}: \mathrm{Ag}$ nanoparticles. XRD was used to check the purity, crystallinity of the nanocrystals and also to detect the presence of $\mathrm{Ag}$. In Fig. 3(a) all the diffraction peaks of the product can be indexed to hexagonal wurtzite structure with lattice points $a=b=3.253 \AA$ and $c=5.213 \AA$ (JCPDS no. 89-1397). The crystallite size calculated from most intense peaks $\left(2 \theta=36.300^{\circ}\right)$ by Scherrer's formula was found to be $\sim 45 \mathrm{~nm}$. Fig. 3(b) depicts the XRD pattern of $\mathrm{ZnO}: \mathrm{Ag}$ a

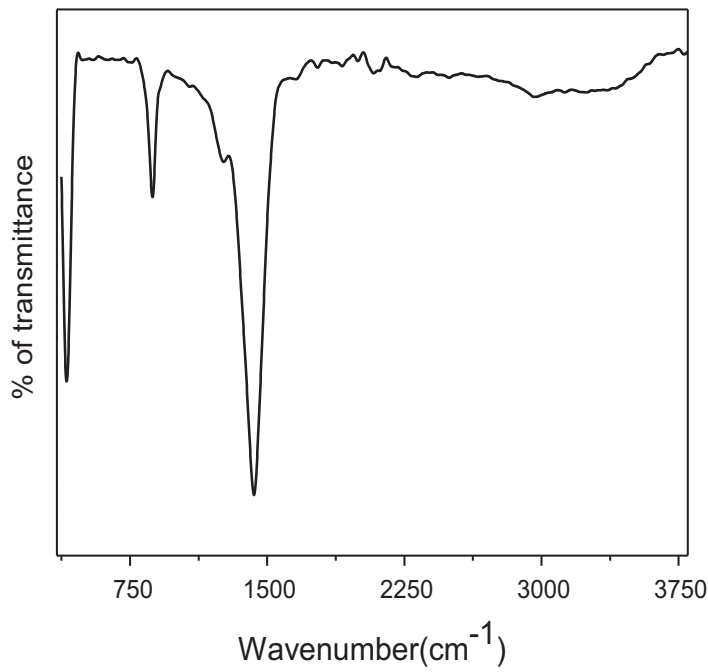

b

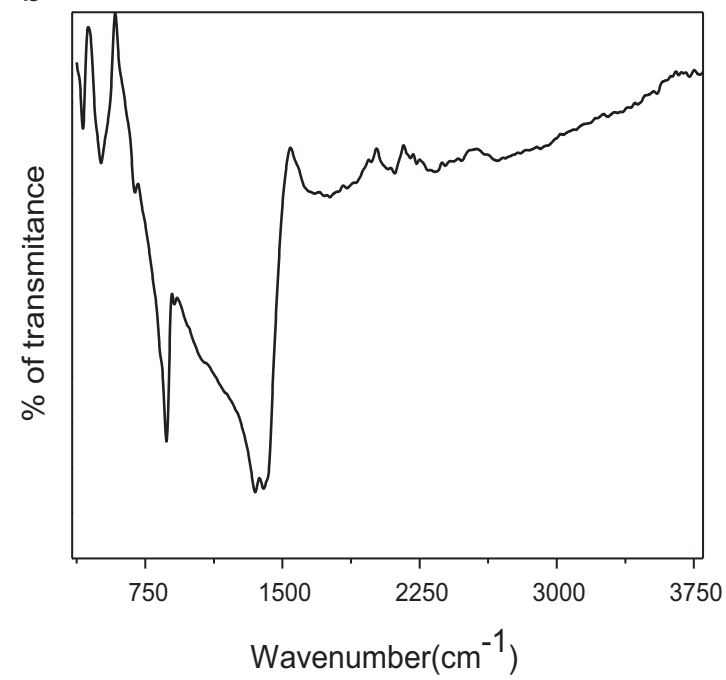

Fig. 4. (a) FTIR spectrum of the $\mathrm{ZnO}$ and (b) $\mathrm{ZnO}: \mathrm{Ag}$ nanoparticles. 
nanoparticles. It was found that in addition to the hexagonal wurtzite $\mathrm{ZnO}$ structure, the diffraction peaks at two theta values $37.900,43.800$ and 64.300 can be assigned to cubicphase Ag (JCPDS no.4-783) [20]. This clearly indicates the presence of $\mathrm{Ag}$ in $\mathrm{ZnO}$ crystal lattice. The crystallite size calculated from most intense peak $\left(2 \theta=36.1^{\circ}\right)$ by Scherrer's

a

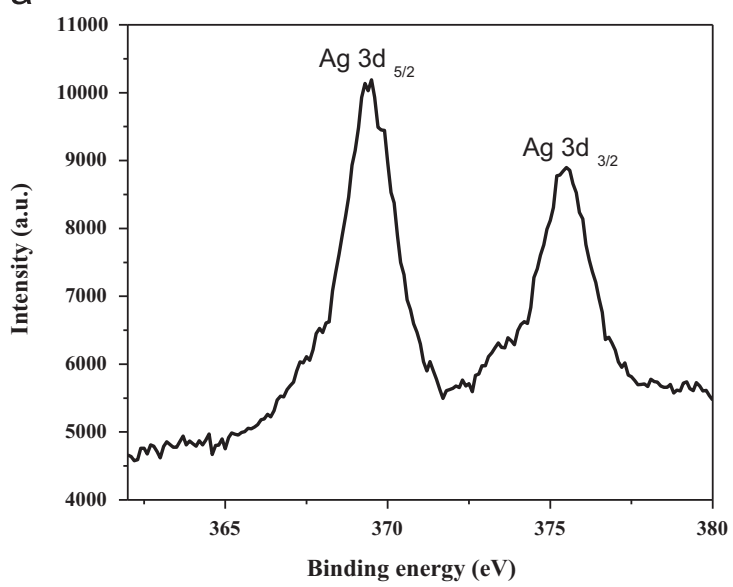

C

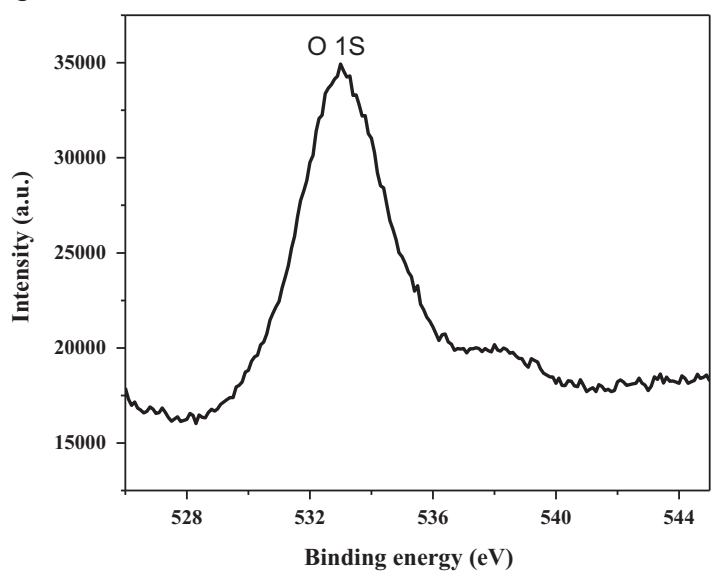

formula was found to be at $\sim 40 \mathrm{~nm}$. FTIR spectra of un-doped and doped ZnO nanoparticles are shown in Fig. 4(a) and (b) respectively. A broad peak at $\sim 3336 \mathrm{~cm}^{-1}$ (Fig. 4(a)) indicates the presence of hydroxyl residue which is due to the atmospheric moisture [35,36]. The spectral region from 850 to $1450 \mathrm{~cm}^{-1}$ shows the presence of carbonated impurities [37].

b

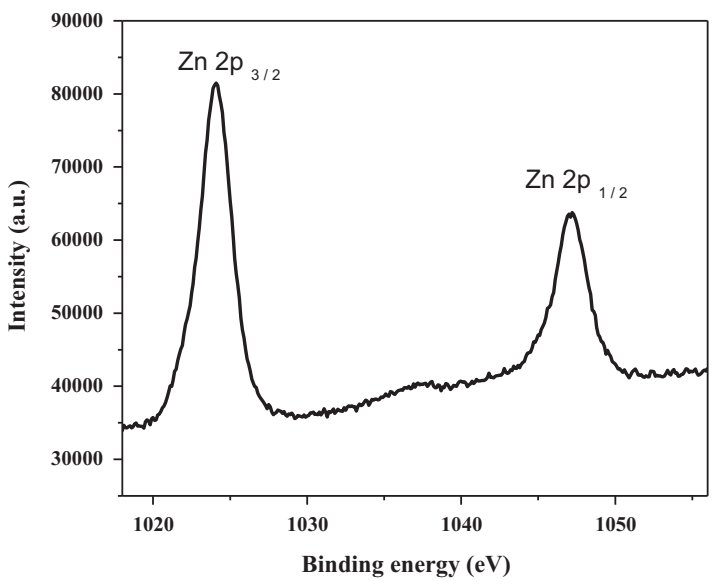

d

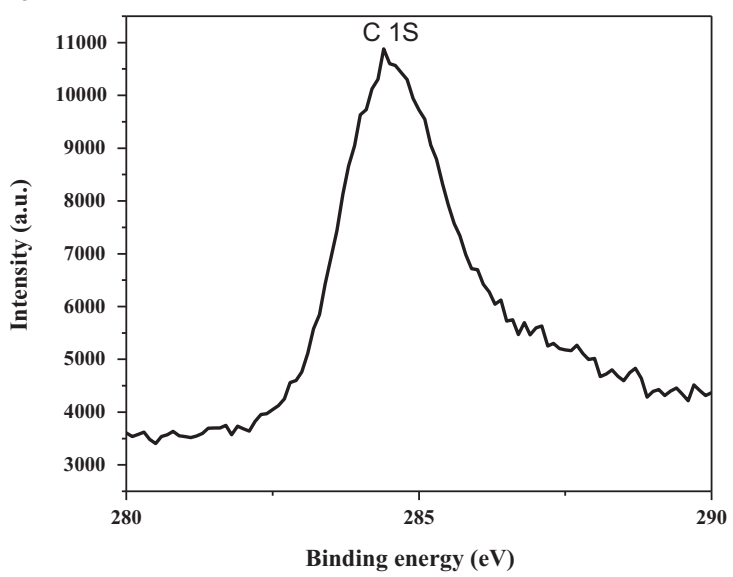

e

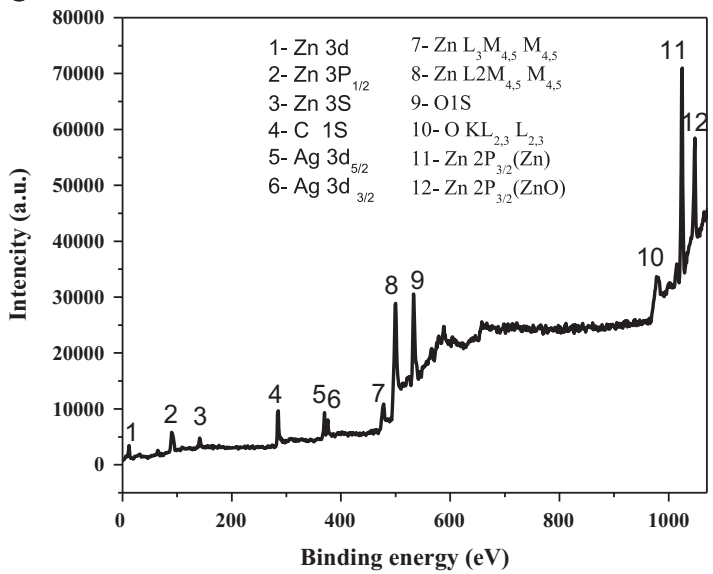

Fig. 5. (a) XPS spectra of Ag, (b) Zn, (c) O, (d) C and (e) wide spectrum of ZnO:Ag nanoparticles, 
A peak at $408 \mathrm{~cm}^{-1}$ is associated with the characteristic vibrational mode of $\mathrm{Zn}-\mathrm{O}$ bond [38,39]. Significant spectroscopic (Fig. 4(b)) bands at $405 \mathrm{~cm}^{-1}$ and $510 \mathrm{~cm}^{-1}$ can be assigned to $\mathrm{Zn}-\mathrm{O}$ and $\mathrm{Ag}-\mathrm{ZnO}$ vibrational stretching frequencies respectively [40-43]. XPS spectra of Ag 3d, Zn 2p, O 1s, C1s and wide spectrum of $\mathrm{ZnO}: \mathrm{Ag}$ is shown in Fig. 5. XPS measured at the $\mathrm{Ag} 3 \mathrm{~d}$ core levels (Fig. 5 (a)), i.e., $\mathrm{Ag} 3 \mathrm{~d} \mathrm{5/2}$ and $\mathrm{Ag} 3 \mathrm{~d} 3 / 2$ binding energies appeared at $369 \mathrm{eV}$ and $375 \mathrm{eV}$, respectively. This is in good agreement with metallic silver values [44,45]. XPS spectrum of Zn 2p (Fig. 5(b)), shows two peaks at $1024 \mathrm{eV}$ for $\mathrm{Zn} 2 \mathrm{p} 3 / 2$ corresponds to the hydroxyl groups attached to the $\mathrm{Zn}$ ions on the surface of nanoparticles [46]. Another peak at $1044.200 \mathrm{eV}$ corresponds to $\mathrm{Zn}$ atoms bonded to oxygen atoms to form $\mathrm{ZnO}$ instead of $\mathrm{Zn}-\mathrm{C}-\mathrm{O}$ alloys [47]. XPS spectrum of O1s (Fig. 5(c)) shows strong peak at $530.200 \mathrm{eV}$ which is the characteristic of lattice oxygen in $\mathrm{ZnO}: \mathrm{Ag}$ [48]. XPS spectrum of $\mathrm{C} 1 \mathrm{~s}$ is shown in Fig. 5(d). It shows strong peak $\sim 284.300 \mathrm{eV}$ which can be assigned to C-O groups [49]. The overall XPS spectrum of

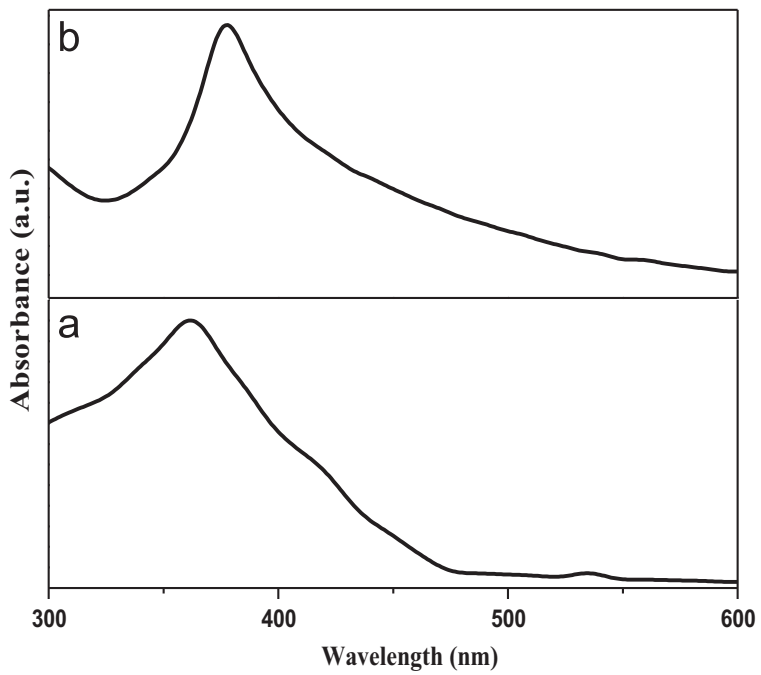

Fig. 6. (a) UV-visible spectrum of the $\mathrm{ZnO}$ and (b) $\mathrm{ZnO}: \mathrm{Ag}$ nanoparticles.
ZnO:Ag nanoparticles are as shown in Fig. 5(e) where all the peaks observed in the spectrum were in agreement with the earlier reports [50].

Fig. 6 shows the UV-vis spectra of the $\mathrm{ZnO}$ and $\mathrm{ZnO}: \mathrm{Ag}$ nanoparticles. Pure $\mathrm{ZnO}$ nanoparticles (Fig. 6(b)) show a maximum absorbance at $360 \mathrm{~nm}$ corresponding to a band gap of $3.460 \mathrm{eV}$ which was blue shifted compared to that of bulk $\mathrm{ZnO}$ nanoparticles ( $3.370 \mathrm{eV}$ ). The blue shift may be due to quantum size effects, [51]. Fig. 6(b) shows the maximum absorbance at $378 \mathrm{~nm}$ corresponding to a band gap of $3.100 \mathrm{eV}$, which was red shifted compared to undoped as well as bulk $\mathrm{ZnO}$. It clearly indicates that Ag was successfully inserted into the $\mathrm{ZnO}$ crystal lattice. This indicates that $\mathrm{ZnO}: \mathrm{Ag}$ nanoparticles have much stronger absorption than that of $\mathrm{ZnO}$ nanoparticles, i.e., $\mathrm{ZnO}$ :Ag nanoparticles possess higher photocatalytic activity than undoped $\mathrm{ZnO}$ nanoparticles [52]. Fig. 7(a) and (b) showed the room temperature PL spectrum of the both undoped and doped $\mathrm{ZnO}$ nanoparticles respectively. Both the spectra showed a strong, broad UV emission at $380 \mathrm{~nm}$, which comes from the band edge recombination of free excitation [53] and sharp peak at $512 \mathrm{~nm}$, has been assigned to oxygen vacancy 'Vo' and substitution defects [54]. SEM images of $\mathrm{ZnO}$ and $\mathrm{ZnO}: \mathrm{Ag}$ nanoparticles (Fig. 8(a) and (b)) show that the nanoparticles are agglomerated during the formation stage itself to form very tiny crystals. Fig. 8(c) and (d) clearly shows the presence of bright $\mathrm{Ag}$ nanoparticles on the surface of ZnO. TEM images (Fig. 9) showed irregular sized, almost spherical shaped nanoparticles with average size $58 \mathrm{~nm}$ and $52 \mathrm{~nm}$ for undoped and doped $\mathrm{ZnO}$ nanoparticles respectively. BET surface area of the $\mathrm{ZnO}$ and $\mathrm{ZnO}: \mathrm{Ag}$ nanoparticles were found to be $40.110 \mathrm{~m}^{2} / \mathrm{g}$ and $71.210 \mathrm{~m}^{2} / \mathrm{g}$ respectively. It is clear from BET studies that $\mathrm{ZnO}: \mathrm{Ag}$ has a higher surface area, hence enhanced photocatalytic activity.

\subsection{Photocatalytic activity of $\mathrm{ZnO}$ and $\mathrm{ZnO}: \mathrm{Ag}$ nanoparticles}

\subsubsection{Effect of dye concentration}

Fig. 10 shows the effect of dye concentration on the photocatalytic activity of $\mathrm{ZnO}$ and $\mathrm{ZnO}: \mathrm{Ag}$ nanoparticles. a

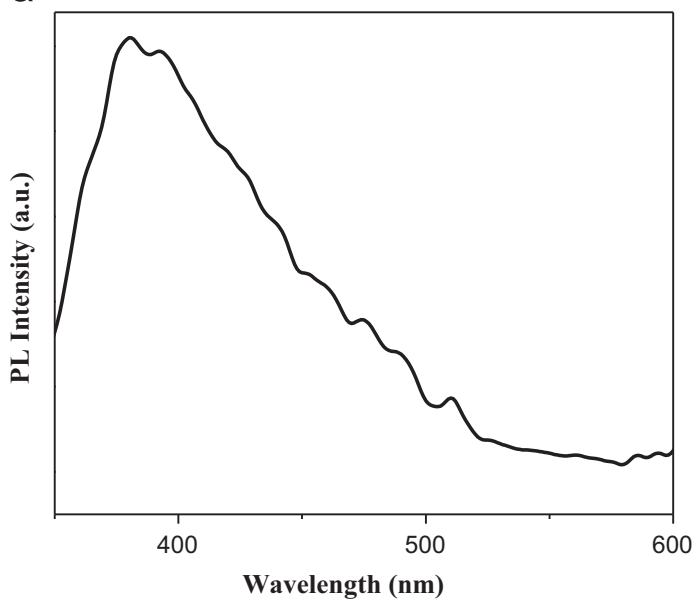

b

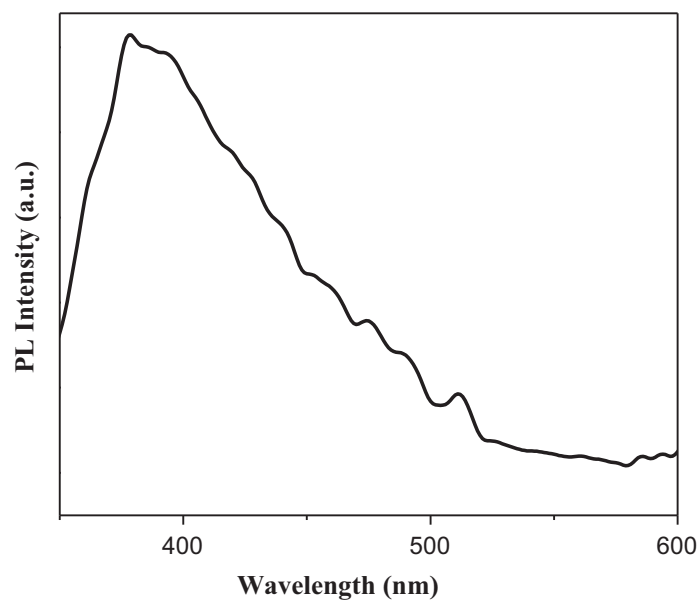

Fig. 7. (a) Photoluminescence spectrum of the $\mathrm{ZnO}$ and (b) $\mathrm{ZnO}: \mathrm{Ag}$ nanoparticles. 

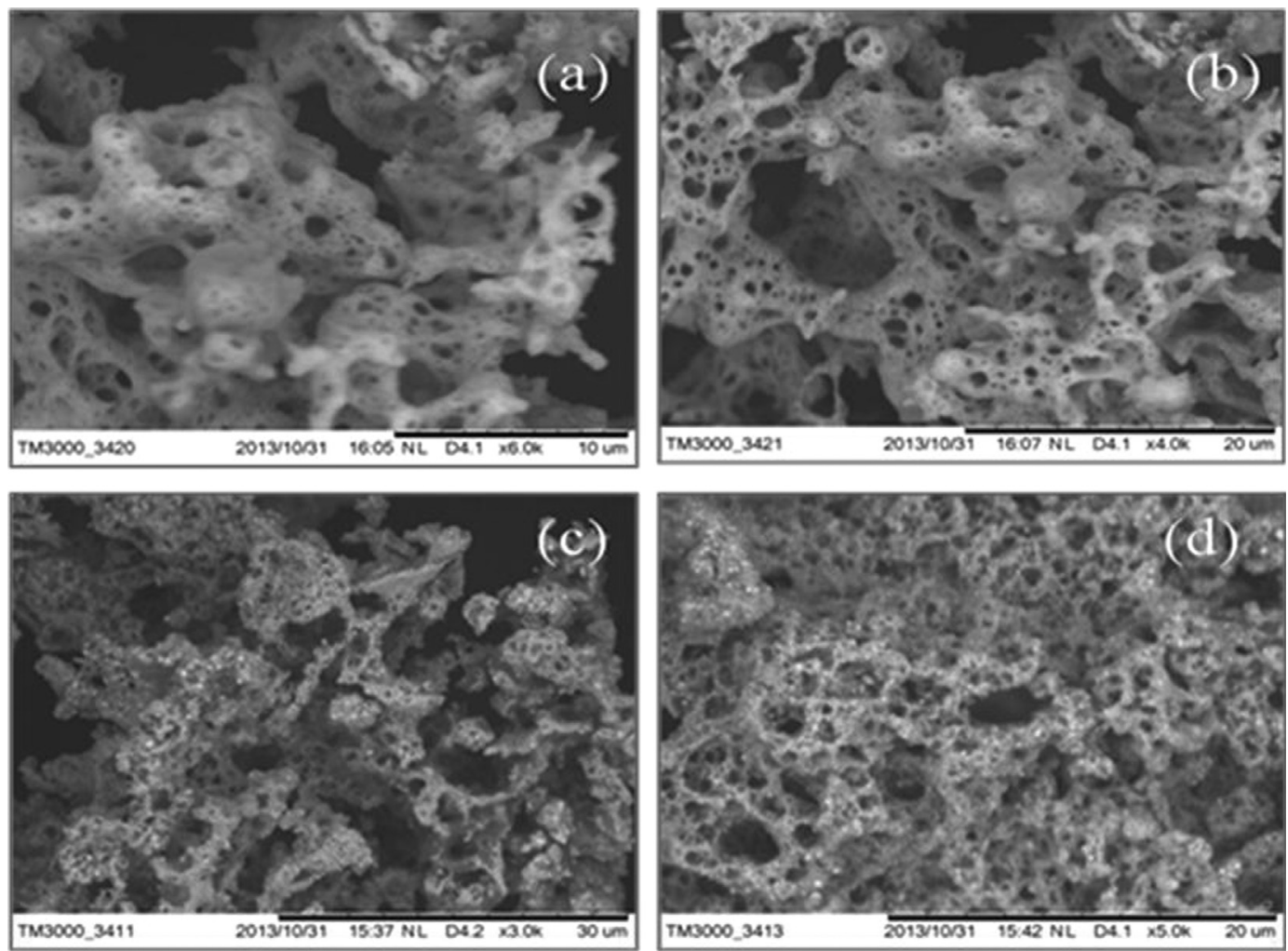

Fig. 8. (a) and (b) SEM images of the $\mathrm{ZnO}$ and (c) and (d) $\mathrm{ZnO}$ :Ag nanoparticles.
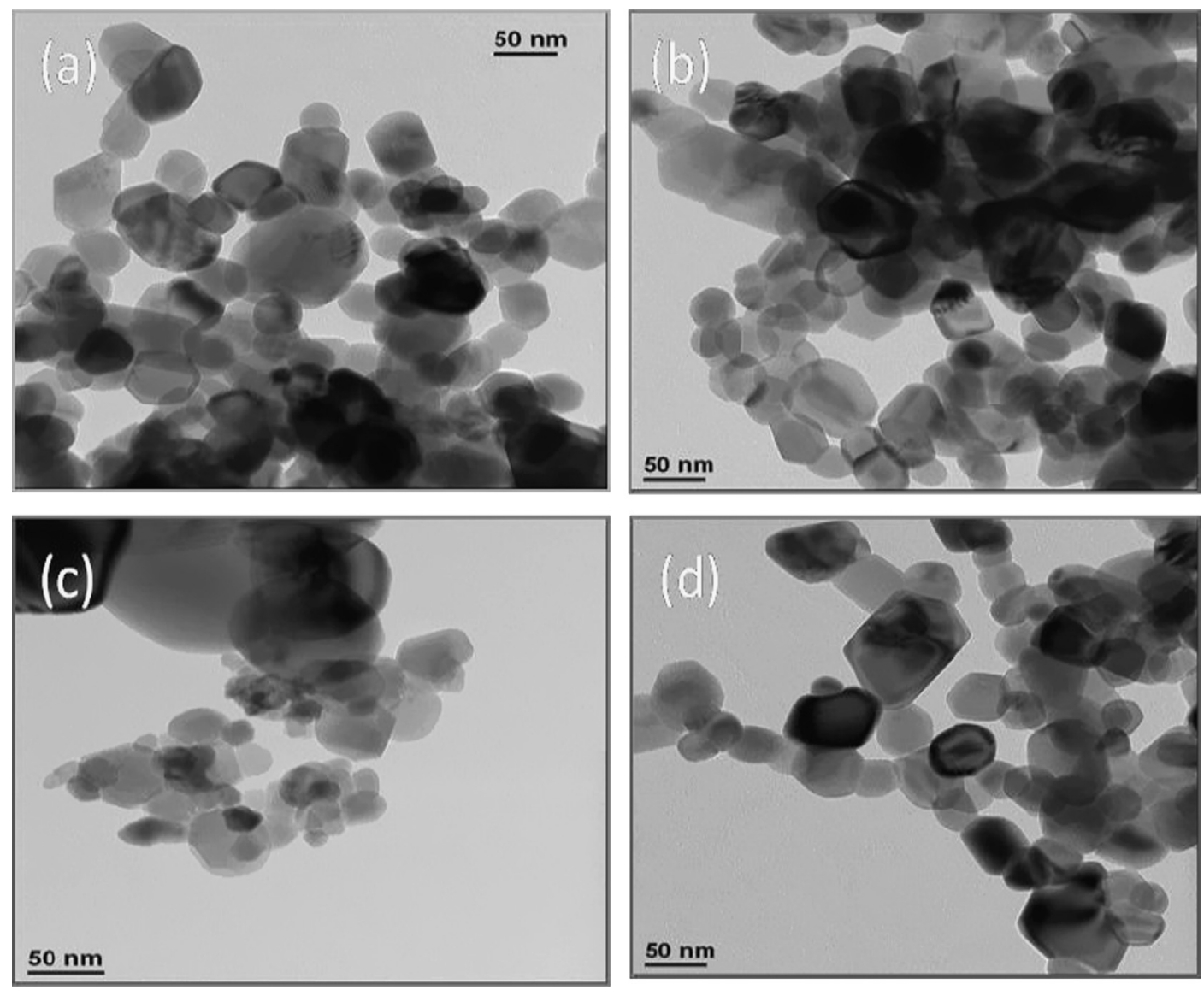

Fig. 9. (a) and (b) TEM images of the $\mathrm{ZnO}$ and (c) and (d) $\mathrm{ZnO}: \mathrm{Ag}$ nanoparticles. 
Experimental parameters are, concentration of trypan blue (TrB): $5-25 \mu \mathrm{g} / \mathrm{L}$, amount of catalyst: $100 \mathrm{mg} / 100 \mathrm{~mL}$ and $\mathrm{pH}: 10$. As the concentration of dye increases, time taken for complete degradation increases. At increased concentrations more dye molecules are adsorbed on to the surface of catalyst resulting in decreased active sites on the catalyst (lesser number of hydroxyl and superoxide radicals) and thereby, reduced light penetration. $\mathrm{ZnO}$ and $\mathrm{ZnO}: \mathrm{Ag}$ nanoparticles degrade $5 \mu \mathrm{g} / \mathrm{L}$ dye solution completely after $120 \mathrm{~min}$ and 90 min of illumination respectively, whereas for $25 \mu \mathrm{g} / \mathrm{L}$ dye solution degradation efficiency is 70\% (Fig. 10(a)) and $80 \%$ (Fig. 10(a)) after $120 \mathrm{~min}$ for $\mathrm{ZnO}$ and $\mathrm{ZnO}: \mathrm{Ag}$, respectively.

\subsubsection{Effect of catalyst dose}

Effect of catalytic load on the photocatalytic degradation of dye is shown in Fig. 11. In order to determine the optimal dosage of the catalysts; the catalytic load was varied from $0.250 \mathrm{mg} / 100 \mathrm{~mL}$ to $1.500 \mathrm{mg} / 100 \mathrm{~mL}$. The optimized load was found to be $1.250 \mathrm{mg} / 100 \mathrm{~mL}$. Below this optimum load, active sites on the surface of the catalyst increases resulting in rapid degradation. Above the optimum load, turbidity of the slurry increases, light penetration decreases and thus, availability of hydroxides and super oxides become minimal. Fig. 11(a) and (b) shows that $1.250 \mathrm{mg} / 100 \mathrm{~mL}$ of dye solution degraded completely at $90 \mathrm{~min}$ and $75 \mathrm{~min}$ for $\mathrm{ZnO}$ and $\mathrm{ZnO}$ : $\mathrm{Ag}$ nanoparticles respectively.

\subsubsection{Effect of $\mathrm{pH}$ on photocatalytic degradation}

The $\mathrm{pH}$ of a dye solution is very important for degradation and is as shown in Fig. 12. From the figure it is clear that photocatalytic degradation efficiency is more in basic condition than in acidic condition. This observation matches well with the reported studies [55,56]. The variation of $\mathrm{pH}$ alters the surface properties of $\mathrm{ZnO}$ and $\mathrm{ZnO}: \mathrm{Ag}$ nanoparticles, in turn, dissociation of the dye molecules. At $\mathrm{pH} 10$, perhydroxyl radicals are formed, leading to the formation of hydrogen peroxide which gives more number of hydroxyl radicals. The highest photocatalytic degradation observed in both the cases is at $\mathrm{pH} 10$. Mechanisms of formation of possible radicals are as shown in Eqs. (2)-(11).

$\mathrm{O}_{2}+\mathrm{e}^{-} \rightarrow \mathrm{O}_{2}^{--}$ a

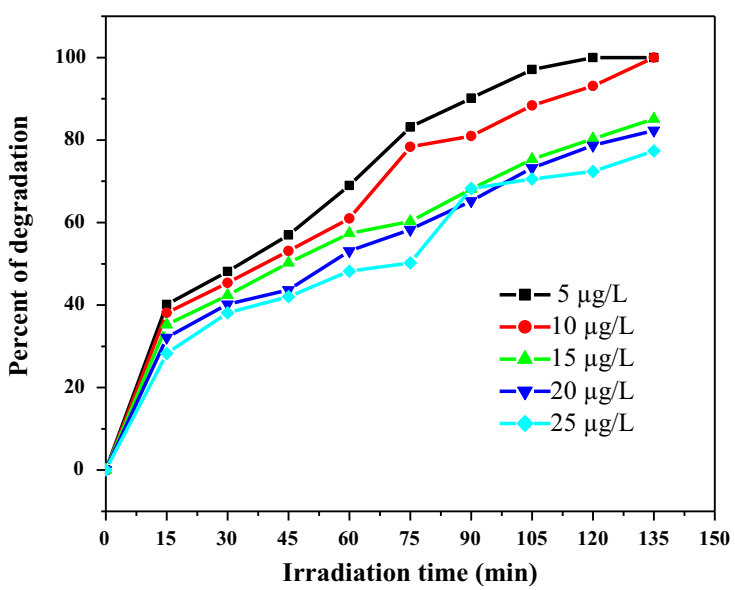

b

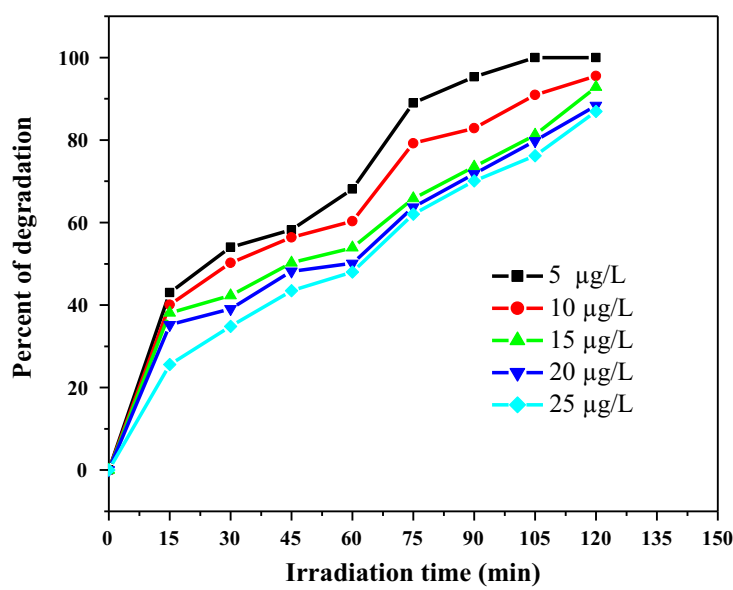

Fig. 10. (a) Effect of dye concentration on the photocatalytic process of the $\mathrm{ZnO}$ and (b) ZnO:Ag nanoparticles.

a

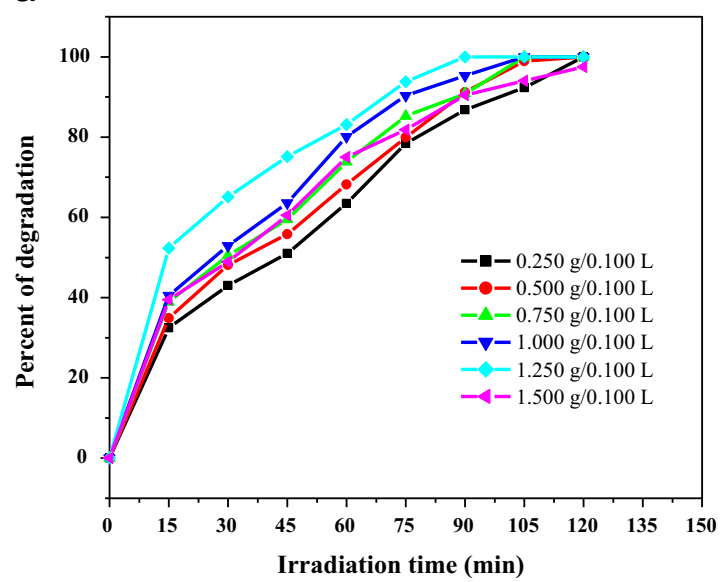

b

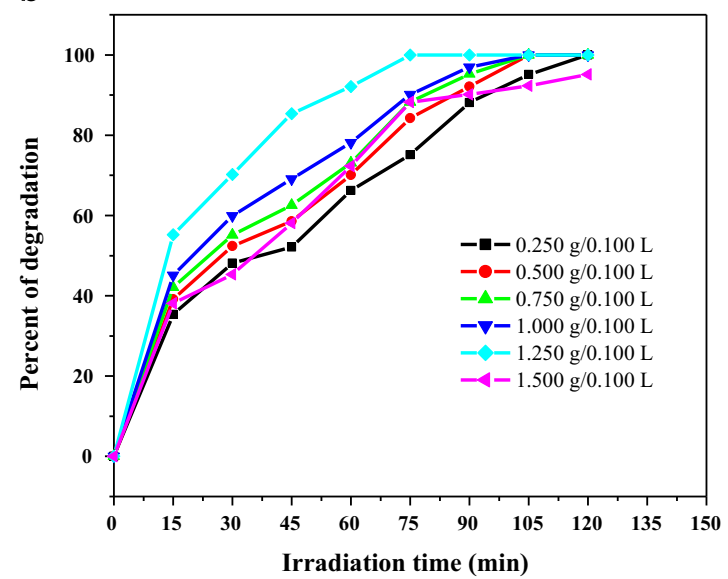

Fig. 11. (a) Effect of catalytic load on the photocatalytic process of the $\mathrm{ZnO}$ and (b) ZnO:Ag. 
a

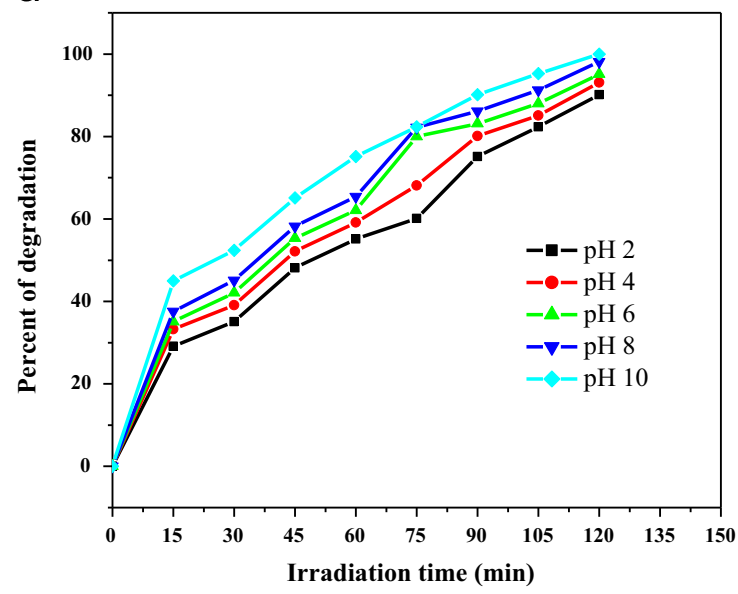

b

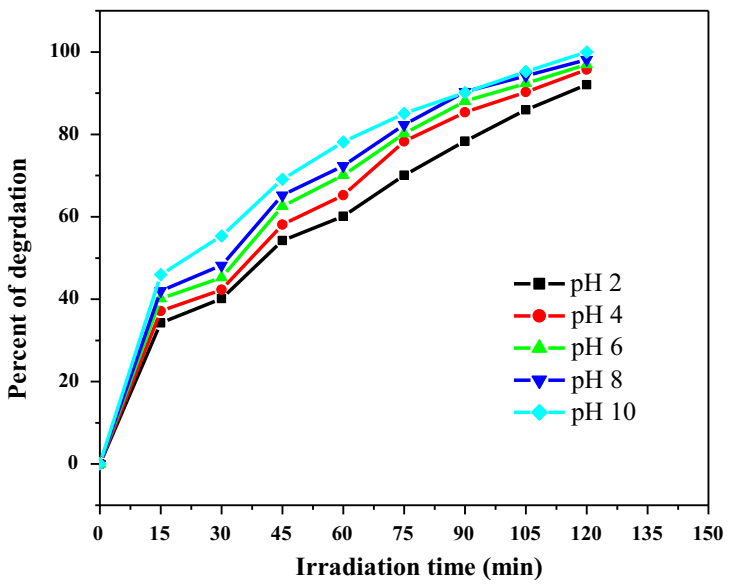

Fig. 12. (a) Effect of $\mathrm{pH}$ on photocatalytic process of the $\mathrm{ZnO}$ and (b) $\mathrm{ZnO}: \mathrm{Ag}$ nanoparticles.

$\mathrm{O}_{2}^{\cdot-}+\mathrm{H}^{+} \rightarrow \mathrm{HO}_{2}$.

$\mathrm{HO}_{2} \cdot+\mathrm{HO}_{2} \cdot \rightarrow \mathrm{H}_{2} \mathrm{O}_{2}+\mathrm{O}_{2}$

$\mathrm{H}_{2} \mathrm{O}_{2}+\mathrm{e}_{\mathrm{cb}}^{-} \rightarrow \mathrm{HO}^{\bullet}+\mathrm{HO}^{-}$

$\mathrm{H}_{2} \mathrm{O}_{2}+\mathrm{O}_{2} \cdot \rightarrow \mathrm{HO}^{\bullet}+\mathrm{HO}^{-}+\mathrm{O}_{2}$

$\mathrm{H}_{2} \mathrm{O}_{2} \rightarrow 2 \mathrm{HO}^{\circ}$

$\mathrm{O}_{2}+\mathrm{HO}^{-} \rightarrow \mathrm{O}_{2} \cdot+\mathrm{HO}^{\cdot}$

Dye $+\mathrm{OH} \rightarrow$ degradation products

Dye $+\mathrm{h}_{\mathrm{VB}^{+}} \rightarrow$ oxidation products

Dye $+\mathrm{e}_{\mathrm{CB}^{-}} \rightarrow$ reduction products

3.1.4. Comparative study of photocatalytic activity of $\mathrm{ZnO}$ and $\mathrm{ZnO}: \mathrm{Ag}$ nanoparticles

Fig. 13 shows the comparative study of photocatalytic activity of $\mathrm{ZnO}$ and $\mathrm{ZnO}: \mathrm{Ag}$ nanoparticles. Photocatalytic reaction was carried out at constant dye concentration $(5 \mu \mathrm{g} / \mathrm{L})$ and catalytic load $(500 \mathrm{mg} / 100 \mathrm{~mL})$ at $\mathrm{pH} 10$. The above experiment clearly indicates that the photocatalytic activity of $\mathrm{ZnO}: \mathrm{Ag}$ nanoparticles were superior to ZnO nanoparticles [57].

\subsubsection{Determination of quantum yield of $\mathrm{ZnO}$ and $\mathrm{ZnO}: \mathrm{Ag}$} nanoparticles

Quantum yield or photonic efficiency of the photocatalyst is studied using UV-visible spectrometer and spectro-flurophotometer. Quinine sulfite is used as standard and quantum yield can be calculated by the formula

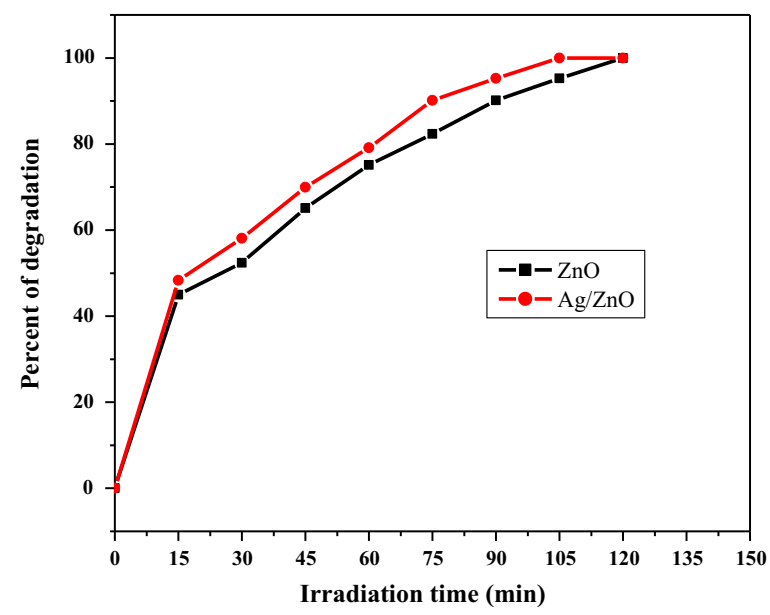

Fig. 13. Comparison study of photocatalytic activity of undoped and ZnO:Ag nanoparticles.

Table 1

Absorbance and integrated fluorescence intensity of quinine sulfite.

\begin{tabular}{lc}
\hline Absorbance & Integrated fluorescence intensity \\
\hline 0.201 & 15946.518 \\
0.295 & 2222.754 \\
0.409 & 30019.625 \\
0.500 & 37803.570 \\
0.598 & 45428.728 \\
0.710 & 55759.227 \\
\hline
\end{tabular}

as shown in the Eq. (12).

$Q_{\text {unknown }}=\frac{Q_{\text {known }} \times(\text { Slope }) \text { unknown } \times \eta^{2} \text { unknown }}{(\text { Slope })_{\text {known }} \times \eta^{2} \text { known }}$

$Q$ is quantum yield, $\eta$ is refractive index of solvent used and slope can be calculated by plotting absorbance vs integrated fluorescence intensity. The quantum yield of $\mathrm{ZnO}$ photocatalyst is 0.616 and the quantum yield of $\mathrm{ZnO}: \mathrm{Ag}$ photocatalyst is 0.634 i.e. photocatalytic efficiency of $\mathrm{ZnO}: \mathrm{Ag}$ is $3 \%$ higher than that of the bare $\mathrm{ZnO}$ nanoparticles [58]. Absorbance, 
Table 2

Absorbance and integrated fluorescence intensity of $\mathrm{ZnO}$ photocatalyst.

\begin{tabular}{ll}
\hline Absorbance & Integrated fluorescence intensity \\
\hline 0.060 & 17881.857 \\
0.236 & 28269.217 \\
0.313 & 41010.281 \\
0.537 & 65103.938 \\
0.698 & 75177.632 \\
0.815 & 85901.147 \\
\hline
\end{tabular}

Table 3

Absorbance and integrated fluorescence intensity of $\mathrm{ZnO}: \mathrm{Ag}$ photocatalyst.

\begin{tabular}{ll}
\hline Absorbance & Integrated fluorescence intensity \\
\hline 0.052 & 15570.726 \\
0.140 & 28842.163 \\
0.270 & 42318.405 \\
0.400 & 54811.578 \\
0.548 & 63331.578 \\
0.748 & 78487.165 \\
\hline
\end{tabular}

a

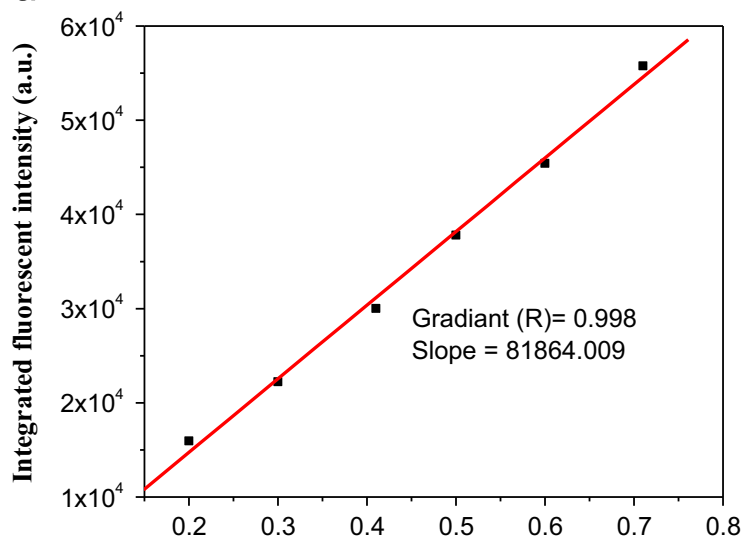

Absorbance (a.u.) integrated fluorescence intensity of quinine sulfite, $\mathrm{ZnO}$, and ZnO:Ag nanoparticles are shown in Tables 1-3 respectively. Graph of absorbance vs integrated fluorescence intensity of quinine sulfite, $\mathrm{ZnO}$, and $\mathrm{ZnO}: \mathrm{Ag}$ nanoparticles are shown in Fig. 14(a)-(c) correspondingly.

3.1.6. Determination of adsorption equilibrium of $\operatorname{Tr} B$ on the nanoparticles surfaces

In order to investigate the adsorption and absorption equilibria of $\mathrm{TrB}$ on the surfaces of $\mathrm{ZnO}$ and $\mathrm{ZnO}: \mathrm{Ag}$ nanoparticles, the reaction was carried out in dark. The concentration of dye is varied from 5 to $25 \mu \mathrm{g} / \mathrm{L}$, catalytic load is $1.250 \mathrm{mg} / 100 \mathrm{~mL}$ and $\mathrm{pH}$ of the solution is 10 . The suspensions are allowed to attain equilibrium in the dark under continuous stirring. The slurry is withdrawn for every $30 \mathrm{~min}(10 \mathrm{~mL})$, and then centrifuged. The absorbance of the supernatant was measured to determine the concentration of dye and the experimental results are shown in Fig. 15. We noticed that the adsorption and absorption equilibria of $\mathrm{TrB}$ on the surfaces of $\mathrm{ZnO}$ and $\mathrm{ZnO}: \mathrm{Ag}$ nanoparticles are found to be $60 \mathrm{~min}$ and $65 \mathrm{~min}$,

b

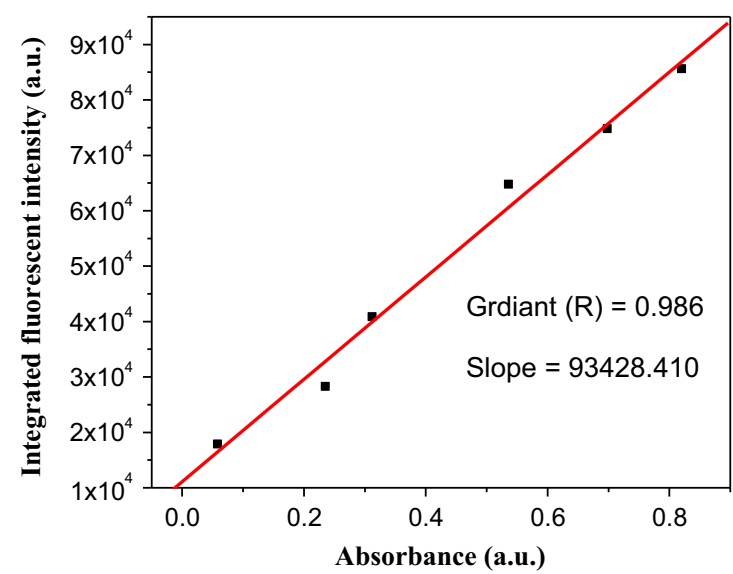

C

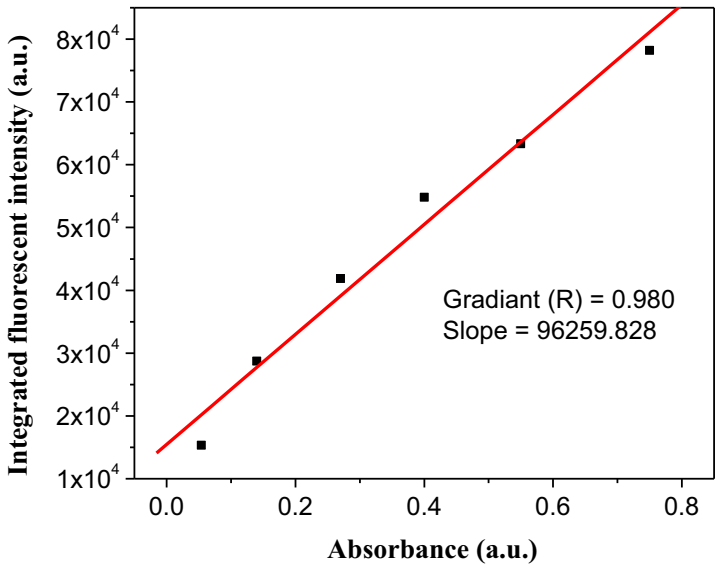

Fig. 14. (a) Graph of absorbance vs integrated fluorescence intensity of quinine sulfite, (b) $\mathrm{ZnO}$ and (c) $\mathrm{ZnO}$ :Ag nanoparticles. 
a

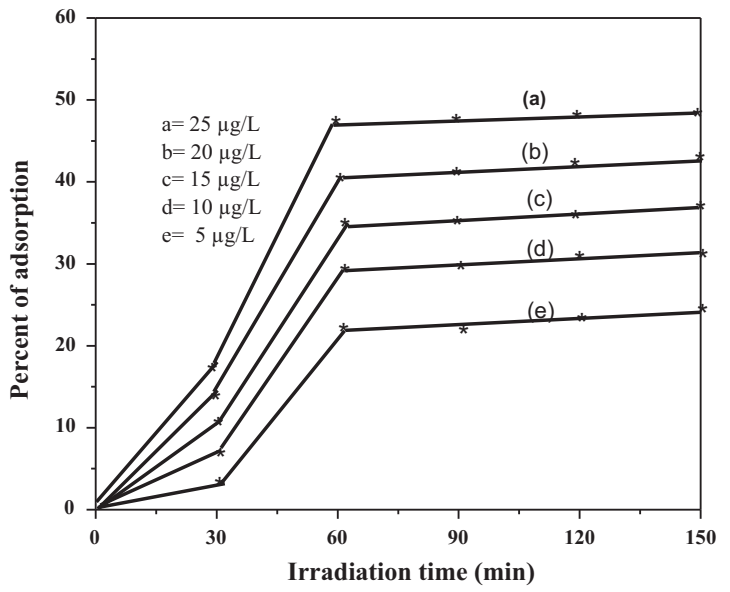

b

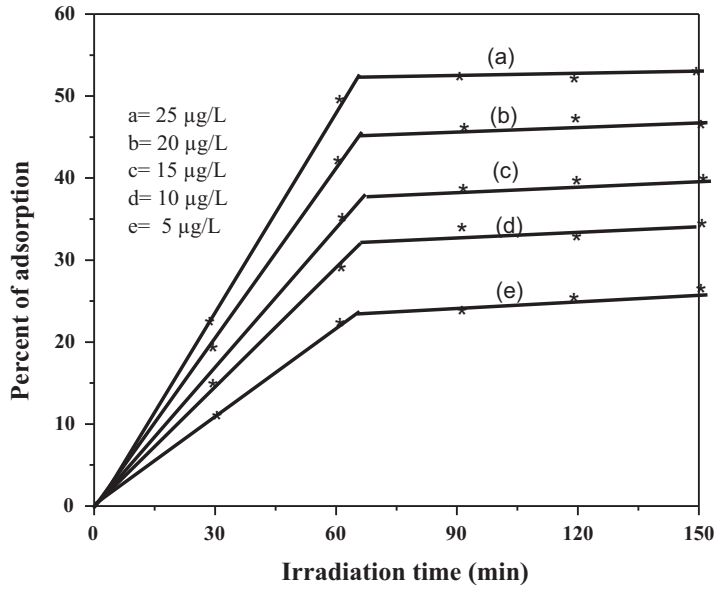

Fig. 15. (a) Adsorption and absorption behavior of dye on the surface of $\mathrm{ZnO}$ and (b) $\mathrm{ZnO}: \mathrm{Ag}$.

respectively. Beyond this time the dye could not be degraded [59].

\section{Conclusion}

We have successfully synthesized $\mathrm{ZnO}$ and $\mathrm{ZnO}: \mathrm{Ag}$ nanoparticles via the low temperature solution combustion method. PXRD pattern of doped $\mathrm{ZnO}$ clearly shows the presence of $\mathrm{Ag}$ in the $\mathrm{ZnO}$ matrix. FTIR shows a band at $405 \mathrm{~cm}^{-1}$ and $510 \mathrm{~cm}^{-1}$ due to $\mathrm{Zn}-\mathrm{O}$ and $\mathrm{Ag}-\mathrm{ZnO}$ vibrational stretching. XPS data clearly shows the incorporation of Ag into the $\mathrm{ZnO}$ crystal lattice. UV-vis absorption spectrum of $\mathrm{ZnO}: \mathrm{Ag}$ nanoparticles show red shift compared to the undoped $\mathrm{ZnO}$ nanoparticles. PL spectrum of the $\mathrm{ZnO}$ and $\mathrm{ZnO}: \mathrm{Ag}$ nanoparticles showed a strong UV emission at around $380 \mathrm{~nm}$. TEM images showed that nanoparticles are almost spherical in shape and the average size of the $\mathrm{ZnO}: \mathrm{Ag}$ particles were found to be $52 \mathrm{~nm}$. ZnO:Ag nanoparticles possess higher surface area than the $\mathrm{ZnO}$ nanoparticles. $\mathrm{ZnO}$ :Ag nanoparticles show very good photocatalytic activity than bare $\mathrm{ZnO}$ nanoparticles for the degradation of trypan blue dye.

\section{Acknowledgment}

One of the authors, Ravishankar T.N. acknowledges Jain University for providing financial support to carry out the research work.

\section{References}

[1] T.P. Yendrapati, K.V. Rao, V.S. Saikumar, B.S. Kumari, Adv. Nanopart. 2 (2013) 45-49.

[2] M.A. Ali, M.R. Idris, M.E. Quayum, J. Nanostruct. Chem. 3 (2003) 36-39.

[3] A. Rahman, R. Jayaganthan, R. Chandra, Mater. Sci. Semicond. Process. 18 (2014) 15-21.

[4] R. Georgekutty, M.K. Seery, S.C. Pillai, J. Phys. Chem. C 112 (2008) 13563-13570.

[5] X. Yin, W. Que, D. Fei, F. Shen, Q. Guo, J. Alloys Compd. 524 (2012) $13-21$.

[6] A.B. Djuris, Y.H. Leung, C.H. Choy, K.W. Cheah, W.K. Chan, Appl. Phys. Lett. 84 (2004) 2635-2637.
[7] Y. Nosaka, Ohta Nobuhiro, Miyama Hajime, J. Phys. Chem. 9 (1990) 3152-3155.

[8] T.Y. Kim, J.Y. Kim, S.H. Lee, H.W. Shim, S.H. Lee, E.K. Suh, K.S. Nahma, Synth. Met. 144 (2004) 61-68.

[9] N.F. Djaja, R. Saleh, Mater. Sci. Appl. 4 (2013) 145-152.

[10] J. BandaraH. Weerasinghe, Sol. Energy Mater. Sol. Cells 85 (2005) 385-390.

[11] M. Ahmad, E. Ahmed, Y. Zhang, Z. Hong, Curr. Appl. Phys. 13 (2013) 697-704.

[12] N. Assi, M. Sharif, H. Bakhtiari, M. Naeini, Int. J. Nano Dimens. 5 (2014) 145-154.

[13] R.B. Reed, D.A. Ladner, J.F. Ravvile, Environ. Toxicol. Chem. 31 (2012) 93-99.

[14] L. Gao, S.T. Yang, S. Li, Y. Meng, H. Wang, H. Lei, J. Appl. Toxicol. 33 (2013) 1079-1088.

[15] F. Mohamad, Eur. J. Exp. Biol. 3 (2013) 97-103.

[16] O. Bondarenko, K. Juganson, A. Ivask, A. Kahru, Arch. Toxicol. 87 (2013) 1181-1200.

[17] S. Azizi, M.B. Ahamad, M.Z. Hussein, N.A. Ibrahim, Molecules 18 (2013) 6269-6280.

[18] M.A. Rahman, S. Mahmud, A.K. Alias, A.F. Nor., J. Phys. Sci. 17 (2013) 24-38.

[19] O. Altıntas Yıldırım, H.E. Unalan, C. Durucan, J. Am. Ceram. Soc. 96 (2013) 766-773.

[20] T. Wang, Z. Jiao, T. Chen, Y. Li, W. Ren, S.Y. Bi, Nanoscale 5 (2013) $7552-7557$.

[21] P.V. Kamat, Chem. Rev. 93 (1993) 267-300.

[22] A.H. Shah, E. Manikandan, V. Ganesan, J. Nanomed. Nanotechnol. 2 (2013) 4-8

[23] C. Karunakaran, V. Rajeswari, P. Gomathisankar, Mater. Sci. Semiocond. Process. 14 (2001) 133-138.

[24] F. Meng, H. Lu, ISRN Metallurgy Article ID 429818, 2013.

[25] F. Meng, H. Lu, Adv. Eng. Mater. 11 (2009) 198-201.

[26] R. Wang, J.H. Xin, Y. Yang, H. Liu, L. Xu, J.Hu, J. Appl. Surf. Sci. 227 (2004) 312-317.

[27] T. Jan, J. Iqbal, M. Ismail, M. Zakaullah, S.H. Naqvi, N. Badshah, Int. J. Nanomed. 9 (2013) 3679-3687.

[28] G. Nagaraju, T.N. Ravishankar, K. Manjunatha, S. Sarkar, H. Nagabhushana, R. Goncalves, J. Dupont, Mater. Lett. 109 (2013) 27-30.

[29] K. Namratha, K. Byrappa, J.Bai, J. Biomater. Tissue Eng. 33 (2013) 190-195.

[30] P.S. Sathish Kumar, A. Manivel, S. Anandan, Water Sci. Technol. 59 (2009) 1423-1430.

[31] X. Li, Y. Wang, J. Alloys Compd. 509 (2011) 5765-5768.

[32] B.M. Nagabhushana, R.P. Sreekanth, K.P. Ramesh, C. Shivakumara, G. T. Chandrappa, Mater. Res. Bull. 41 (2006) 1735-1746.

[33] K.C. Patil, S.T. Aruna, T. Mimani, Curr.Opin. Solid State Mater. Sci. 6 (2002) 507-512.

[34] N.K. Daud, B.H. Hameed, Desalination Water Treat. 37 (2012) 1-7.

[35] R. Wahab, S.G. Ansari, K. Seo, G.S. Kim, Mater. Res. Bull. 42 (2007) $1640-1648$.

[36] T.K. Gupta, P.L. Hower, J. Appl. Phys. 50 (1992) 4849-4853.

[37] K. Nejati, Z. Rezvani, R. Pakizevand, Int. Nano Lett. 1 (2011) 75-81. 
[38] G. Shan, L. Xu, G. Wang, Y. Liu, J. Phys. Chem. C 111 (2007) 3290-3293.

[39] K. Sarvari, A. Gangly, T. Ahamd, Bull. Mater. Sci. 35 (2012) 377-381.

[40] M. Faisal, S.B. Khan, M.M. Rahman, A. Jama, Appl. Surf. Sci. 258 (2011) 672-677.

[41] S.B. Khan, M. Faisal, M.M. Rahman, A. Jamal, Talanta 85 (2011) 943-949.

[42] M. Faisal, S.B. Khan, M.M. Rahman, A. Jamal, Chem. Eng. 173 (2011) 178-184.

[43] M.M. Rahmanan, M. Faisal, ACS Appl. Mater. Interfaces 3 (2011) 1346-1351.

[44] E. Sumesh, M.S. Bootharaju, A.T. Pradeep, J. Hazard. Mater. 189 (2011) 450-457.

[45] Y. Lai, H. Zhang, K. Xie, D. Gong, Z. Chen, New J. Chem. 34 (2010) 1335-1340.

[46] A. Sharma, B.P. Sing, S. Dhar, A. Gondorf, M. Spasova, Surf. Sci. 13 (2013) 606-609.

[47] S. De, A. Layek, S. Bhattacharya, D.K. Das, A. Kadir, A. Bhattacharya, S. Dharand, A. Chowdhury, Appl. Phys. Lett. 101 (2012) 121919-121923.

[48] R.H. Heuberger, A. Rossian, N.D. Spencer, Biol. Lett. 3 (2007) 183-185.
[49] A.P. Dementjev, A. Graaf, M.C.M. van de Sanden, K.I. Maslakov, A.V. Naumkin, A.A. Serov, Diam. Relat. Mater. 9 (2000) 1904-1907.

[50] M. Gabás, S. Gota, J.R. Ramos, M. Sánchez, N.T. Barrett, J. Avila, M. Sacchi, Appl. Phys. Lett. 86 (2005) 042104-042107.

[51] Y. Altıntas, H.E. Emrah, D. Caner, J. Am. Ceram. Soc. 3 (2013) 766-769.

[52] A.H. Shah, E. Manikandan, M. Basheer, V. Ganesan, J. Nanomed. Nanotechnol. 3 (2013) 2-6.

[53] D. Qin, Y. Guangruiy, H.E.Z. Guox, Q. Zhang, L.I. Luyao, Chalcogenide Lett. 9 (2012) 441-443.

[54] N.P. Mohabansi, V.B. Patil, N.A. Yenkie, Rasayan J. Chem. 4 (2011) 814-817.

[55] K. Byrappa, A.K. Subramani, S. Ananda, K.M. Lokanatha Rai, M.H. Sunitha, Bull. Mater. Sci. (2007) 30-33.

[56] S. Likius, H. Daniel, N. Nagai, M. Yoshida, Sato, Catalysts 3 (2013) 625-645.

[57] B.N. Patil, D.B. Nayak, V.S. Shrivastava, J. Appl. Chem. Res. 13 (2010) $13-17$.

[58] L. Irimpan, V.P. Nampoori, P. Radhakrishnan, Chem. Phys. Lett. 455 (2008) 265-269.

[59] K.M. Joshi, V.S. Shrivatava, Int. J. Nano Dimens. 2 (2012) 241-252. 